\title{
Primary Side Constant Power Control Scheme for LED Drivers Compatible with TRIAC Dimmers
}

\author{
Junming Zhang ${ }^{\dagger}$, Ting Jiang ${ }^{*}$, Lianghui $\mathrm{Xu}^{*}$, and Xinke $\mathrm{Wu}^{*}$ \\ $\dagger^{*}$ College of Electrical Engineering, Zhejiang University, Hangzhou, China
}

\begin{abstract}
This paper proposes a primary side constant power control scheme for TRIAC dimmer compatible LED drivers. The LED driver is a Flyback converter operated in boundary conduction mode (BCM) to minimize the switching loss. With the proposed control scheme, the input power of the Flyback converter can be controlled by the TRIAC dimming angle, which is not affected by AC input voltage variations. Since the output voltage is almost constant for LED loads, the output current can be changed by controlling the input power with a given conversion efficiency. The isolated feedback circuit is eliminated with the proposed primary side control scheme, which dramatically simplifies the whole circuit. In addition, the input current automatically follows the input voltage due to the BCM operation, and the resistive input characteristic can be achieved which is attractive for TRIAC dimming applications. Experimental results from a $15 \mathrm{~W}$ prototype verify the theoretical analysis.
\end{abstract}

Key words: Flyback, LED driver, PFC, Primary side control, TRIAC

\section{INTRODUCTION}

With the rapid development of high brightness LED technologies, both the performance and the cost of phosphor converted white LEDs (WLED) has improved significantly. The efficacy (light output per watt) of WLED is now competitive with compact fluorescent lamps [1], [2]. Solid state lighting technology using LEDs as an efficient lighting source for commercial and residential lighting has recently become more attractive.

The most convenient way to use LED lighting is to replace existing lighting fixtures directly to reduce cost and avoid waste [3], [4]. The replacement of incandescent lamps with LED bulbs is already ongoing in many countries to reduce carbon emissions and save energy. However, there are still a lot of new issues during this direct replacement.

The most important issue of replacement is related to dimming [5], [6]. Although there are quite a lot of dimming methods, the dominant domestic and architectural dimming systems are based on TRIAC (phase-cut) dimmers. A traditional lighting system using a TRIAC dimmer and an incandescent bulb is shown in Fig.1. A variable resistor $R_{2}$ can be used to adjust the dimming angle (firing angle or

Manuscript received Oct. 31, 2012; revised Apr. 12, 2013.

Recommended for publication by Associate Editor Sangshin Kwak.

${ }^{\dagger}$ Corresponding Author: zhangjm@zju.edu.cn

Tel: +86-571-87953095, Fax: +86-571-8795-2224, Zhejiang University

${ }^{*}$ College of Electrical Engineering, Zhejiang University, China phase angle) $\theta$, as shown in Fig. 1, i.e. the energy delivered to the lamp. For the proper operation of a TRIAC, it has minimum latching current and holding current requirements. When a TRIAC is triggered, the voltage across the device must be sufficient to enable the flow of the minimum latching current. After the device has been latched, a continuous holding current must flow through the device in one direction [7].

An incandescent lamp is purely resistive and works well with a TRIAC dimmer because the lamp resistance can provide sufficient damping to the parasitic ring and holding current to the TRIAC dimmer after it has been triggered.

However, LED lamps are totally different from purely resistive bulbs, which results in a considerable difference in the way the dimmer works. Since a LED should be powered by a DC current, there is a LED driver to convert the AC input to the required DC output. The conventional low power LED driver has an input rectifier bridge and a capacitive input filter as shown in Fig. 2. Therefore, the current is drawn from the input only during a very short period when the input voltage exceeds the DC bus voltage, and it drops below the holding current quickly. It is not possible to control the TRIAC conduction angle in such a circuit, which may cause issues like flickering, audible noise, improper dimming function or even damage of the lamp or dimmer [5]-[6]. Special design efforts are necessary to make LED drivers compatible with TRIAC dimmers. 


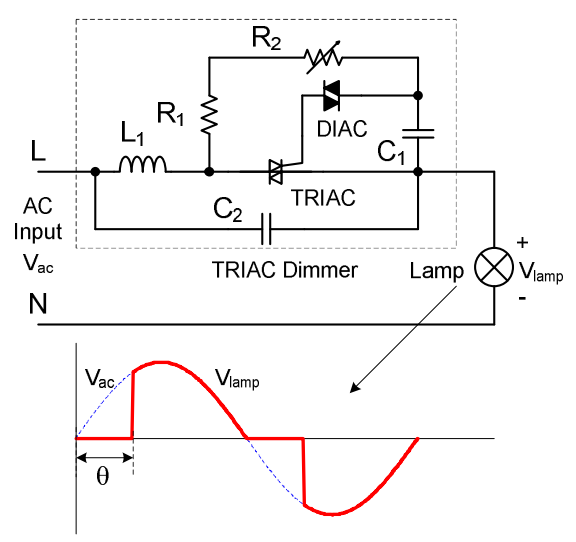

Fig. 1. Conventional incandescent bulb with TRIAC dimmer.
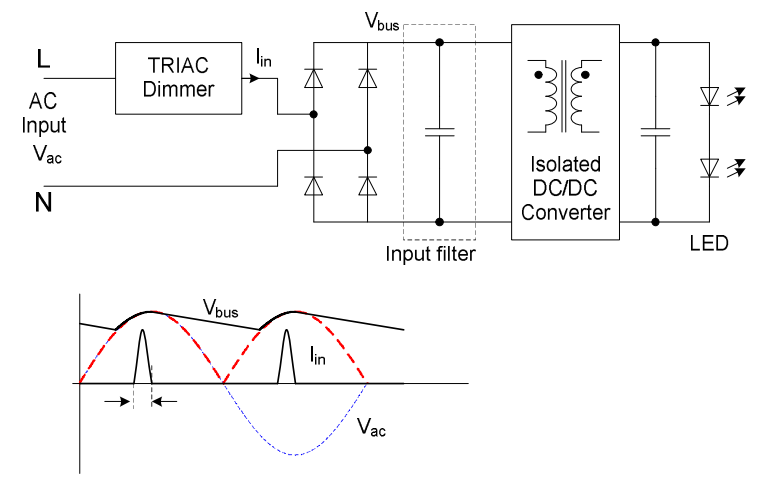

Fig. 2. Conventional LED driver with TRIAC dimmer.

Generally, in order to be compatible with a TRIAC dimmer, the input characteristic of a LED driver should be similar to those of an incandescent lamp. Therefore, the input current needs to follow the input voltage like a resistor even under the dimming condition. The power factor correction (PFC) technique is a simple way to achieve such input characteristics. Furthermore, for lighting equipment above $25 \mathrm{~W}$, the low-frequency harmonics must comply with the EN 61000-3-2, Class C regulation. In addition, the Energy Star requirement for Solid State Lighting Luminaires is $\mathrm{PF}>0.7$ for residential and $\mathrm{PF}>0.9$ for commercial [8]. Therefore, the $\mathrm{PFC}$ function is a general requirement for LED drivers.

The conventional two stage method with a front-end PFC converter is too costly and complex for low power LED driver applications. A lot of PFC techniques with a single switch for LED driver applications have been proposed [9]-[12]. However, all of them need an isolated feedback circuit for output current control, which is complex. In addition, the opto-isolator in the feedback loop also affects the output performance due to the current transfer ratio degradation caused by temperature rises. Furthermore, the TRIAC dimming capability has not been discussed [9].

To meet safety requirements, the output of a LED driver is usually galvanic isolated. The TRIAC dimming signal is detected in the transformer primary side while the output current is sensed in the secondary side. An extra galvanic isolation circuit is required to implement the dimming function and the output current regulation, which further complicates the whole circuit.

In order to further reduce cost and size, regulation of the output current in the primary side is preferred. Many primary side control schemes have been proposed for the Flyback topology [13]-[20]. Most of them are only suitable for discontinuous conduction mode (DCM) operation with a relatively stable DC input, and the primary side peak current is usually fixed in order to achieve a constant output current [13]-[16]. Therefore, they are not able to achieve a high power factor at the same time, which makes them unsuitable for TRIAC dimming applications.

In [17]-[19], primary side current control methods based on switch peak current detection were proposed for Flyback PFC converters. These methods can achieve output current regulation and a high power factor. The most popular industry solutions for TRIAC compatible primary side controlled LED drivers with PFC are based on a similar concept. However, the output current accuracy is affected by the internal delay time and the current rising slew rate [19]-[21]. The output current accuracy with a different delay time is also discussed in [19]. In [20], a more accurate primary side current control method based on the average switch current was proposed. However, the delay time of the zero current detection will affect the output current accuracy.

Based on the issues discussed above, this paper proposes a new primary side constant power control scheme for LED driver applications based on the Flyback topology, which features TRIAC dimming compatible, resistive input characteristic, no isolation feedback circuit and a nearly constant output power. With input voltage and dimming angle signal feedforward, the output current can be controlled and adjusted by the dimming angle, and no secondary side current feedback is required, which dramatically simplifies the whole circuit. The Flyback converter is operated in BCM to minimize the switching loss. The detailed operation principle will be illustrated in section II. The design considerations are given in section III. Section IV will present the experimental results from a $15 \mathrm{~W}$ prototype with a TRIAC dimmer.

\section{PRINCIPLE OF OPERATIONS}

In order to design a LED driver compatible with a TRIAC dimmer, the input characteristic of the LED driver should be resistive. Generally, the conventional PFC control can make the LED driver look like a pure resistor from the AC input side, which helps provide the holding current of the TRIAC dimmer. For low power LED driver applications, the Flyback converter in DCM or BCM operation is widely adopted due to its simplicity and inherent high input PF. A conventional Flyback PFC converter with output current feedback control 


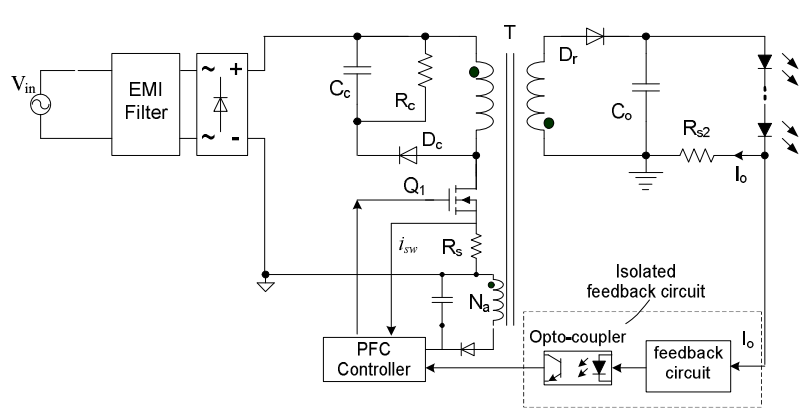

Fig. 3. Flyback PFC with conventional output feedback [22].

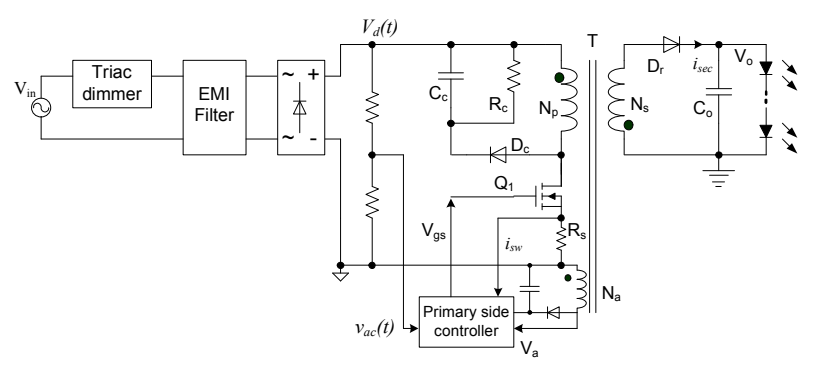

Fig. 4. Flyback PFC with proposed primary side control.

is shown in Fig. 3 [22]-[23]. The average output current is regulated via an isolated feedback circuit. For TRIAC dimming applications, the TRIAC dimming angle detected in the primary side should be transferred to the secondary side and the output current should be changed. Therefore, an extra opto-coupler is usually required. The transformer auxiliary winding $\mathrm{N}_{\mathrm{a}}$ is used to power the primary side control circuit during normal operation. The circuit is quite complex with these isolation circuits.

To simplify the whole circuit, this paper proposes a new primary side constant power control scheme for a Flyback PFC converter compatible for TRIAC dimming applications. The circuit diagram is shown in Fig. 4. The output current or output power regulation and PFC function are achieved by the primary side controller shown in Fig. 5. The detected dimming angle signal at the primary side can be used directly to adjust the output current or power without any isolation circuit.

By comparing Fig. 4 with Fig. 3, it is clear that the isolated circuits shown in Fig. 3 are eliminated by the primary side control method. The circuit is dramatically simplified. The output current is controlled by a primary side controller. And the primary side controller can be an integrated circuit (IC) designed with the required control functions.

The key point of the primary side controller is the implementation of the PFC function and the output current regulation, which are achieved by the proposed primary side constant power control using the feedforward method. Assuming the converter is ideal and the LED forward voltage drop is constant, the output current is proportional to the input power. Therefore, the input power can be used to control the output current with a given output voltage.
Considering the AC input voltage variation in real applications, the input power should be kept constant at a given dimming angle under various AC input conditions, which is achieved by input voltage and dimming angle feedforward control. Generally, for low power Flyback PFC converters, $\mathrm{BCM}$ operation is preferred to minimize the switching loss. In addition, peak current mode (PCM) control and voltage mode control (constant on time control) are two of the most popular control methods to achieve the PFC function. The detailed implementation of the proposed feedforward control scheme along with these two control methods is described as follows.

\section{A. Peak Current Mode Control}

Based on the power stage shown in Fig. 4, the diagram of the proposed primary side control scheme for PCM control is shown in Fig 5. The rectified input voltage $V_{d}(t)$ is used for the input voltage feedforward, the current waveshape and the TRIAC dimming angle detection. These three signals are fed to a multiplier to generate a current reference signal $I_{R E F}(t)$ to set the peak current value of the switch current $I_{s w}$. The transformer third winding voltage signal $V_{a}$ is also used for zero current detection and duty cycle compensation. The steady sate waveforms of the Flyback PFC converter in boundary conduction mode (BCM) operation are shown in Fig. 6.

While $\mathrm{Q}_{1}$ is on, the primary side current (same as the switch current $I_{s w}$ ) increases. As soon as $I_{s w}$ reaches the reference $I_{R E F}(t)$, switch $\mathrm{Q}_{1}$ turns off. The magnetizing current is transferred to the secondary side and decreases linearly. Once the current reaches zero, $Q_{1}$ turns on again. The zero current detection (ZCD) block shown in Fig. 5 is used to detect when the secondary side current reaches zero based on the third winding voltage signal $V_{a}$. Once the secondary side current reaches zero, $V_{a}$ starts to decrease from the reflected output voltage due to resonance between the transformer magnetizing inductor and the circuit parasitic capacitors, which can be used for ZCD.

Fig.7 shows the circuit implementation and the related waveforms of the control blocks shown in Fig.5. $V_{a c}(t)$ is the input voltage waveshape signal derived from the rectified input voltage $V_{d}(t)$ by a simple resistor divider. The feedforward voltage $V_{f f}$ is the average value of $V_{a c}(t)$, which is determined by the AC input voltage amplitude and the dimming angle $\theta$. A low pass filter (LPF) can be used to obtain $V_{f f}$ from $V_{a c}(t)$ as shown in Fig.7(a). The dimming angle detection circuit detects the TRIAC dimming angle $\theta$ and generates a dimming angle voltage signal $V_{t}$ proportional to $\theta$. The comparator compares the rectified input voltage signal $V_{a c}(t)$ with a small threshold (0V shown in Fig. 7) and generates a pulse signal $V_{C M P}$. The $V_{C M P}$ signal has a fixed amplitude $\mathrm{V}_{\mathrm{c}}$ and its pulse width is proportional to the dimming angle $\theta$. The dimming angle voltage signal $V_{t}$ is the average value of $V_{C M P}$ which is also proportional to $\theta$. 


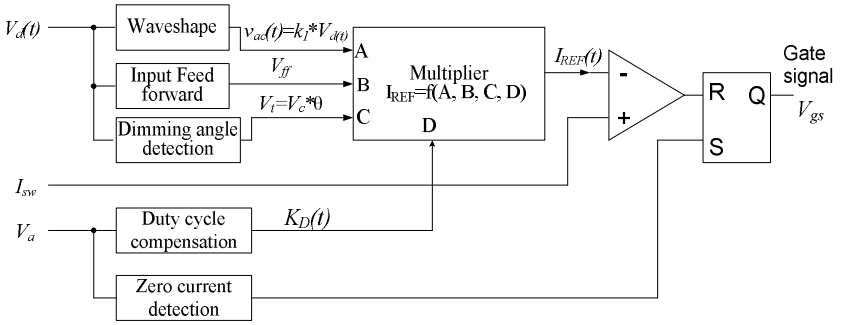

Fig. 5. Proposed primary side control scheme for PCM control.

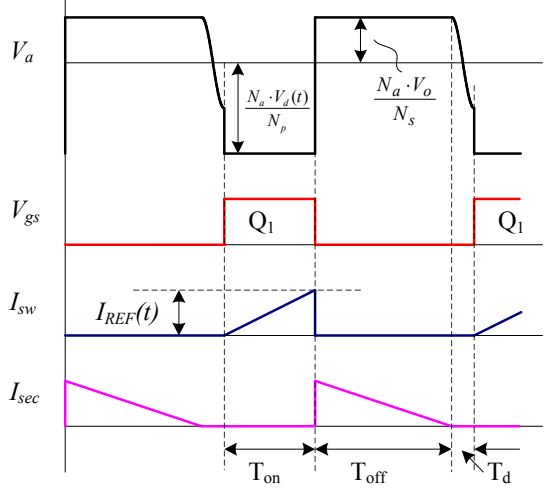

Fig. 6. Steady state waveforms for Flyback PFC in BCM.

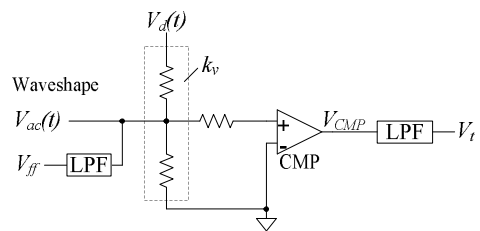

(a) Circuit implementation.

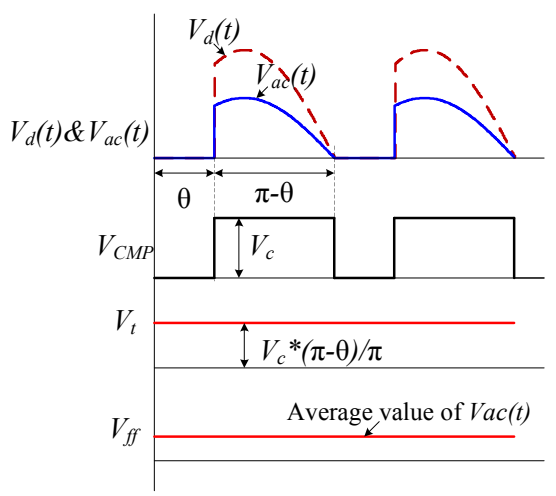

(b) Steady state waveforms.

Fig. 7. Dimming angle detection and input voltage feedforward.

Based on Fig 7, the expressions $V_{f f}, V_{t}$ and $V_{a c}(\mathrm{t})$ are given below.

$$
\begin{gathered}
V_{d}(t)=\mid \begin{array}{l}
0, \quad \text { if } \quad 0 \prec \omega t \leq \theta \\
V_{p} \cdot \sin (\omega t), \quad \text { if } \quad \theta \prec \omega t \leq \pi
\end{array} \\
V_{f f}=\frac{1}{\pi} \cdot \int_{0}^{\pi} k_{v} \cdot V_{d}(t) \cdot d(\omega t)=k_{v} \cdot V_{p} \cdot \frac{1+\cos (\theta)}{\pi} \\
V_{t}=V_{c} \cdot \frac{\pi-\theta}{\pi} \\
V_{a c}(t)=k_{v} \cdot V_{d}(t)
\end{gathered}
$$

where $V_{p}$ is the peak value of the AC input voltage; $\mathrm{k}_{\mathrm{v}}$ is the gain of the resistor divider shown in Fig 7; $\omega$ is the input line frequency in $\mathrm{rad} / \mathrm{s}$; and $V_{c}$ represents the fixed voltage amplitude of the pulsed dimming angle detecting signal.

The waveshape signal $V_{a c}(\mathrm{t})$, the input voltage feed forward voltage $V_{f f}$, the dimming angle signal $V_{t}$ and the duty cycle compensation $K_{D}(t)$ are fed to the multiplier to generate the current reference signal $I_{R E F}(t)$. The current reference can make the input current follow the input voltage waveshape and achieve a constant input power with a given dimming angle and various input voltages, which is given as:

$$
I_{R E F}(t)=k_{m} \cdot \frac{V_{a c}(t) \cdot V_{t}^{m} \cdot K_{D}(t)}{V_{f f}^{2}}, m=2 \text { or } 3
$$

In (5), $\mathrm{k}_{\mathrm{m}}$ is the constant multiplier gain and $\mathrm{m}$ is the coefficient for the dimming angle signal. Unlike the conventional Boost converter, the input current of the Flyback topology is discontinuous. The duty cycle compensation factor $K_{D}(t)$ is used compensate the difference between the average input current and the peak input current. From Fig $6, K_{D}(t)$ is given as:

$$
K_{D}(t)=\frac{2\left(T_{o n}+T_{o f f}+T_{d}\right)}{T_{o n}}
$$

where $T_{\text {on }}$ is the switch on time and $\mathrm{T}_{\text {off }}$ is the secondary side current decreasing time. $T_{d}$ is the delay time between the secondary side current drop to zero and the switch turn on, which depends on the ZCD detecting threshold and the circuit delay. In conventional BCM operation, the delay is usually half the parasitic resonant period in order to minimize the turn on switching loss, which is usually small when compared to the switching period. For the sake of simplicity, this delay time is neglected and $K_{D}(t)$ can be simplified as:

$$
K_{D}(t)=\frac{2\left(V_{d}(t)+N \cdot V_{o}\right)}{N \cdot V_{o}}
$$

where $\mathrm{N}$ is the transformer turn ratio and $V_{o}$ is the output voltage, which can be sampled from the auxiliary winding voltage $V_{a}$ during the flyback period.

Based on (4) to (7), assuming that the input peak current follows the reference current given in (5), the theoretical input power is given in (8), which is also shown in Fig 8(b).

$$
\begin{aligned}
& P_{i n}=\frac{1}{\pi} \cdot \int_{0}^{\pi} V_{d}(t) \cdot \frac{I_{R E F}(t)}{K_{D}(t)} d(\omega t) \\
& =\frac{V_{c}^{m} \cdot k_{m}}{k_{v}} \cdot \frac{(\pi-\theta)^{m}}{(1+\cos \theta)^{2}} \cdot \frac{\pi-\theta+\sin (2 \theta) / 2}{2 \cdot \pi^{m-1}}
\end{aligned}
$$

It is clear that the average input power is not affected by the AC input voltage amplitude and can be controlled by the dimming angle $\theta$.

In some conventional Boost PFC controllers, such as the UC3854, it already utilizes input voltage feedforward to achieve the constant maximum input power limitation at 


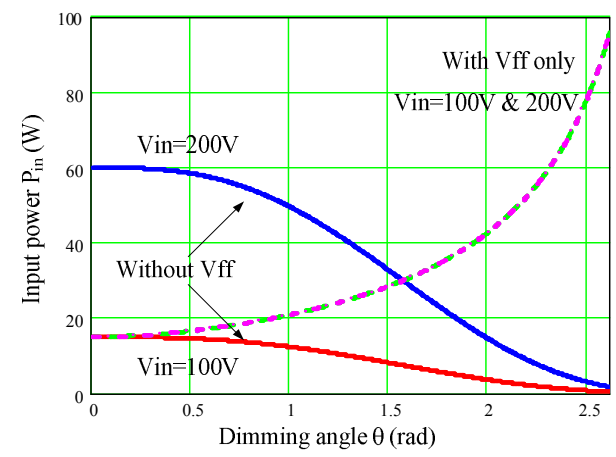

(a) with $V_{f f}$ or $V_{t}$ feedforward only.

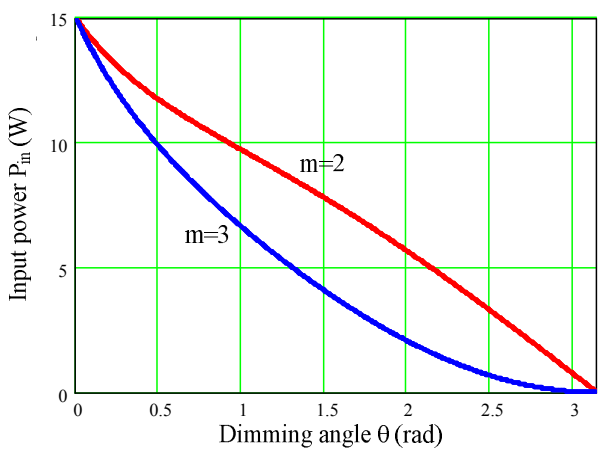

(b) with $V_{f f}$ and $V_{t}$ feedforward.

Fig. 8. Input power vs. $\theta$

different AC input voltages. In TRIAC dimming applications with the Flyback topology, it is no longer effective. Since the input voltage feedforward signal is related to the input voltage amplitude and the dimming angle, the dimming angle signal $\mathrm{V}_{\mathrm{t}}$ should also be included in the current reference to achieve a constant input power at different input voltages.

Fig. 8(a) shows the input power versus the dimming angle $\theta$ with the input voltage feedforward only and with dimming angle signal feedforward only. From Fig 8(a), it can be seen that the input power varies with the input voltage. However, it decreases with an increased dimming angle if there is only a dimming angle signal feedforward. With the input voltage signal feedforward only, the input power increases with an increased dimming angle because the input voltage feedforward signal $V_{f f}$ is also affected by the dimming angle $\theta$ as given in (2). Therefore, there should be a signal that contains the dimming angle information to make the input power decreases with an increased dimming angle $\theta$. Fig. 8(b) shows the average input power with the proposed feedforward control scheme as given in (8) with $\mathrm{m}=2$ and $\mathrm{m}=3$, respectively. It is clear that the input power varies almost linearly with the dimming angle $\theta$ and it is not affected by the input voltage amplitude. To simplify the multiplier calculation, $\mathrm{m}=2$ is usually preferred in practical applications.

The duty cycle compensation is related to the Flyback topology itself. Fig 9 shows the average input power with and without the duty cycle compensation. The theoretical input

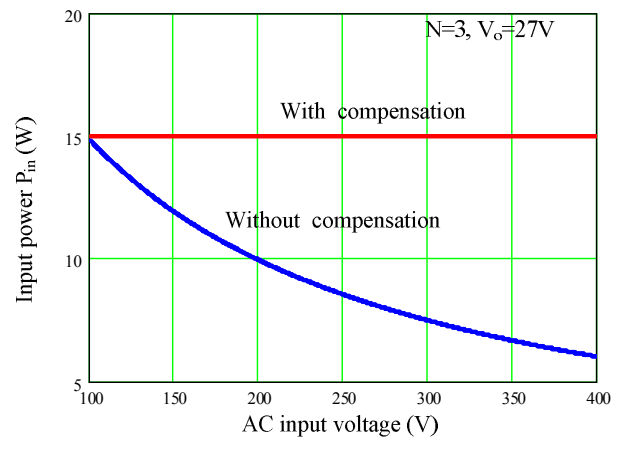

Fig. 9. Input power with and without duty cycle compensation.

power decreases with an increase in the input voltage if there is no duty cycle compensation. It is true that the Flyback converter only draws input current when the primary side switch is on. In addition, the duty cycle of the primary side switch decreases with the input voltage.

\section{B. Voltage Mode Control (Constant on Time Control)}

The PCM control limits the switch current with a calculated current reference $I_{R E F}(t)$ based on feedforward signals. In order to reduce the complexity of the multiplier shown in Fig 5, constant on time control can be used. Constant on time control does not need current waveshape signals. The control circuit diagram is shown in Fig 10, and it differs slightly from Fig 5 . The switch current $I_{s w}$ is replaced by a sawtooth voltage signal generated by a current source and a capacitor. As soon as the voltage on the capacitor reaches the control voltage, the switch turns off. The switch turns on again when the secondary side current reaches zero. The converter is operated in BCM mode and the steady state waveforms are shown in Fig. 6.

The control voltage to determine the on time is given in (9). The switch on time is given in (10). The peak current is automatically proportional to the input voltage and the on time. When compared to the PCM control, the constant on control can be treated as a voltage mode control.

$$
\begin{gathered}
V_{c t r l}(t)=k_{m} \cdot \frac{V_{t}^{2} \cdot K_{D}(t)}{V_{f f}^{2}} \\
T_{o n}(t)=\frac{V_{c t r l}(t) \cdot C_{t}}{I_{c h \arg e}}
\end{gathered}
$$

where $C_{t}$ is the timing capacitor to set the on time and $I_{\text {charge }}$ is the charge current for the timing capacitor, as shown in Fig 10 , which can be treated as constant.

The input power can be derived based on (2), (3), (7), (9) and (10), which is given as:

$$
\begin{aligned}
& P_{\text {in }}=\frac{1}{\pi} \cdot \int_{0}^{\pi} V_{d}(t) \cdot \frac{V_{d}(t)}{L_{p}} \cdot \frac{T_{\text {on }(t)}}{2} \cdot \frac{1}{K_{D}} \cdot d(\omega t) \\
& =\frac{V_{c}{ }^{2} \cdot k_{m}}{k_{v}{ }^{2}} \cdot \frac{(\pi-\theta)^{2}}{(1+\cos \theta)^{2}} \cdot \frac{\pi-\theta+\sin (2 \theta) / 2}{2 \cdot \pi \cdot L_{p}} \cdot \frac{C_{t}}{I_{\text {charge }}}
\end{aligned}
$$




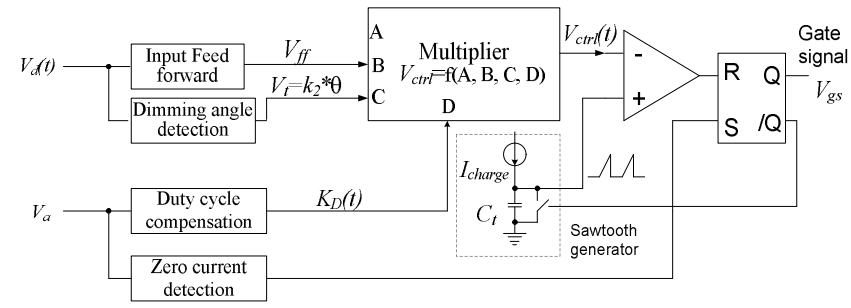

Fig. 10. Control diagram for constant on time.

where $L_{p}$ is the transformer magnetizing inductance.

The input power characteristic is exactly the same as that shown in Fig. 8(b) with $\mathrm{m}=2$ since they have the exact same circuit operation. Comparing (11) and (8), although the input power can be controlled by the dimming angle $\theta$, the input power for constant on time control is also affected by the tolerance of $L_{p}$. This is not preferred for constant input power control since the inductance usually has a large tolerance in real applications, such as $\pm 10 \%$.

\section{DESIGN CONSIDERATIONS}

Based on the analysis given above, the PCM control is attractive due to the fact that the input power is not affected by the primary side inductance tolerance. In the following analysis, the control diagram shown in Fig. 5 will be used.

With the assumption that the output voltage (LED forward voltage drop) is constant and the converter is ideal, the output current can be regulated by regulating the input power. However, the LED forward voltage may have some tolerance, which results in output current tolerance even when the input power is the same. The voltage compensation can be applied to adjust the input power based on the difference between the actual output voltage and the nominal output voltage. Fig. 11 shows the circuit diagram of the output voltage compensation. The output voltage is sampled from the third winding voltage $V_{a}$ after a short delay $\mathrm{T}_{\mathrm{S} \& \mathrm{H}}$ when $\mathrm{Q}_{1}$ is off. Thus the parasitic ring caused by the leakage inductance will not affect the output voltage sampling accuracy. The ratio of the sampled output voltage to the reference voltage is the output voltage compensation factor $\mathrm{K}_{\mathrm{vc}}$. This can be used as an input of the multiplier shown in Fig. 5 to adjust the current reference. To simplify the multiplier, the output voltage compensation factor can be merged into the duty cycle compensation factor given in (7). The new duty cycle compensation factor $K_{D}{ }^{\prime}(t)$ can be expressed as:

$$
K_{D}^{\prime}(t)=\frac{V_{d}(t)+N \cdot V_{o}}{N \cdot V_{o}} \cdot \frac{V_{o}}{V_{R E F}}=\frac{V_{d}(t)+N \cdot V_{o}}{N \cdot V_{R E F}}
$$

where $V_{R E F}$ is the reference for the nominal output voltage.

Therefore, once the output voltage is higher than the nominal value, the input power increases proportionally, which keeps the output current constant.

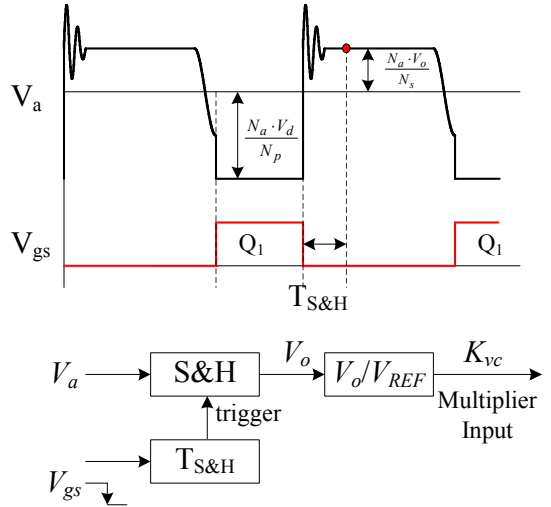

Fig. 11. Circuit block diagram for output voltage compensation.

From (12), the gain of the resistor divider $k_{v}$ to sample $V_{d}(t)$ and the reflected output voltage $N V_{o}$ should be kept the same. The value should be determined by the voltage level required by the controller and the input voltage.

The constant multiplier gain $\mathrm{k}_{\mathrm{m}}$ can also be designed based on the input signal amplitude and the desired current reference amplitude. There are no other restrictions.

The converter efficiency variation is another concern for the output current accuracy especially at the maximum output power. However, the efficiency difference between LED drivers is usually quite small and it is caused by the device tolerances in mass production. A $1 \sim 2 \%$ difference is typical, which means the difference in the output current is also small. As a result, it will not be a big issue when using the proposed constant power control method.

The switching frequency of a Flyback PFC converter always varies with the instant input voltage and load current. Since this has already been analyzed in many studies [24], it will not be repeated here.

\section{EXPERIMENTAL RESULTS}

To verify the proposed constant power control scheme, a LED driver with a $30 \mathrm{~V} / 0.5 \mathrm{~A}$ output and an $\mathrm{AC}$ 160 265Vrms input for TRIAC dimming applications is designed and built. Since there is no commercial integrated circuit (IC) with the desired control function, shown in Fig. 5, it must be built using external circuits. In the prototype, a conventional L6562 PFC controller is used to implement the BCM operation. A S12XS128 microcontroller (MCU) from Freescale is used as an analog multiplier to generate the desired current reference since it is in line frequency.

The bus voltage, the dimming angle signal and the third winding voltage signal are fed to the MCU A/D input. The current reference is calculated by (5) and the duty cycle compensation $K_{D}{ }^{\prime}(t)$ is calculated by (12) considering output voltage compensation. The system diagram of the prototype is shown in Fig. 12. The current reference generated by the MCU is sent to an input of the L6562's internal multiplier and the other input of the multiplier is fixed to $3 \mathrm{~V}$ to set the 


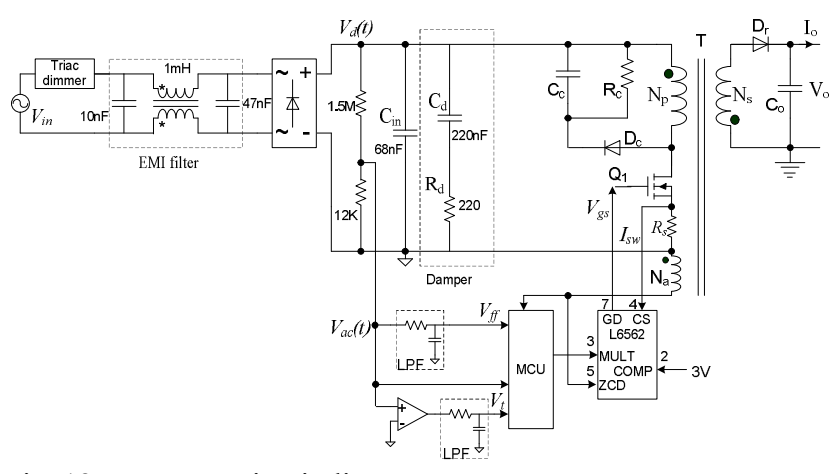

Fig. 12. Prototype circuit diagram.

TABLE I

Key PARAMETERS OF THE EXPERIMENTAL PrototyPe

\begin{tabular}{|l|l|l|}
\hline Parameters & Symbol & Value \\
\hline AC input voltage & $\mathrm{V}_{\text {in }}$ & $160-265 \mathrm{~V}(\mathrm{RMS})$ \\
\hline Output & $\mathrm{V}_{\mathrm{o}} / \mathrm{I}_{\mathrm{o}}$ & $30 \mathrm{~V} / 0.5 \mathrm{~A}$ \\
\hline Primary side inductance & $\mathrm{L}_{\mathrm{p}}$ & $1 \mathrm{mH}$ \\
\hline Transformer Core & & EE25/26/7 \\
\hline Transformer turns ratio & $\mathrm{N}_{\mathrm{p}}: \mathrm{N}_{\mathrm{s}}: \mathrm{N}_{\mathrm{a}}$ & $90: 30: 12$ \\
\hline Primary side switch & $\mathrm{Q}_{1}$ & $\mathrm{P} 10 \mathrm{NK} 70 \mathrm{Z}$ \\
\hline Secondary rectifier & $\mathrm{D}_{\mathrm{r}}$ & F10LC20U \\
\hline Output capacitance & $\mathrm{C}_{\mathrm{o}}$ & $2000 \mathrm{uF} / 35 \mathrm{~V}$ \\
\hline Current sense resistance & $\mathrm{R}_{\mathrm{s}}$ & $0.5 \Omega$ \\
\hline TRIAC dimmer & & Siemens 5TG0 752 \\
\hline
\end{tabular}

current reference. If the maximum AC input is $265 \mathrm{Vrms}$, the resistor divider gain $k_{v}$ should be 0.0079 . Thus the maximum voltage of $V_{a c}(t)$ is around $3 \mathrm{~V}$. In the prototype, the resistor divider is selected as $12 \mathrm{k} \Omega$ and $1.5 \mathrm{M} \Omega$ to minimize the power loss. The key parameters of the prototype are given in Table I.

As shown in Fig. 12, a small film capacitor $C_{\text {in }}$ is used to filter out the switching frequency current ripple. The capacitance of $\mathrm{C}_{\mathrm{in}}$ should be minimized to achieve a high power factor and to limit the inrush current when the TRIAC is on. The input EMI filter is used to suppress the common mode and differential mode noise. Nevertheless, with the inductors, the capacitors in the circuit and the TRIAC dimmer itself, a parasitic ring may occur due to the sudden rising of the input voltage when the TRIAC is on. With a conventional incandescent lamp load, the lamp impedance can damp the ring sufficiently. With a LED lamp, it is a little bit different. The luminaire efficacy of the LED lighting source is usually above $701 \mathrm{~m} / \mathrm{W}$ for well designed lighting fixtures, which is much higher than that of incandescent bulbs. Therefore, for the same light output, the LED lamp consumes much less power. Although LED drivers exhibit a resistive input characteristic with the control scheme mentioned above, the relatively large input impedance may not be sufficient to damp the parasitic ring when the TRIAC turns on. This can cause undesirable behaviors such as flickering or a limited dimming range. An extra damping circuit is used to overcome this issue. A passive damper circuit comprised of $C_{d}$ and $R_{d}$ is used in the prototype, as shown in Fig. 12. The damping capacitance $C_{d}$ should be 3 to 5 times the capacitance of $C_{i n}$. $\mathrm{R}_{\mathrm{d}}$ was selected to minimize the parasitic ringing. In the prototype, the value of $C_{i n}, C_{d}$ and $R_{d}$ are $68 n F, 220 n F$ and 220 Ohm, respectively.

Fig. 13 shows the chopped AC input voltage $V_{\text {in }}$ and the line input current $I_{\text {in }}$ at different dimming angles. It is clear that the input current follows the input voltage and the input characteristic is resistive. In addition, there is no severe parasitic ring with the proper passive damper in the circuit. Due to the limited charge time of the RC inside the TRIAC, the maximum and minimum dimming angles are limited. The minimum dimming angle (maximum output) that can be achieved is $20^{\circ}$ and the maximum dimming angle is around $160^{\circ}$.

Fig. 14 shows the input power $\mathrm{P}_{\text {in }}$ and output power $\mathrm{P}_{\text {out }}$ versus the input voltage $V_{\text {in }}$ under the no dimming condition. From Fig. 14, it is clear that $P_{\text {in }}$ is almost constant with the proposed control scheme. It can also be seen that $\mathrm{P}_{\text {out }}$ is proportional to $\mathrm{P}_{\text {in }}$. The maximum input power variation in the entire input range is around $5.4 \%$. The output current also follows the same shape of the input power, as shown in Fig. 15. The maximum output current difference is around $5.5 \%$, which is almost same as that of $\mathrm{P}_{\text {in }}$. For comparison, the output current variation with the conventional feedback control shown in Fig. 3 is also given in Fig. 15. It is clear that the output current variation is very small when using the conventional isolated feedback circuit. However, it needs an opto-coupler which increases the cost and complexity.

The measured efficiency at the no dimming condition is shown in Fig. 16. The variation is less than $2 \%$ in the entire input range, which is quite small as expected. Fig. 17 shows the power factor $(\mathrm{PF})$ versus the input voltage under the no dimming condition. The PF is well above 0.9 in the entire input range, which can meet the related regulations. Fig. 18 shows the dimming curve at different input conditions. For comparison, the theoretical dimming curve is also shown in Fig. 18. It is clear that these dimming curves match each other quite well when the dimming angle is small. When the dimming angle is increased to a certain level, the output current begins to decrease a little faster due to converter efficiency decreases with a reduced output power and the saturation of the current reference generated by the MCU. Fig.19 and Fig.20 present the input power and output current versus the input voltage at different dimming angles $\theta$, respectively. With the same TRIAC dimming angle, the output current is almost constant at different input voltages. There is small output current fluctuation, which is mainly caused by dimming angle detection errors at different input voltages. 


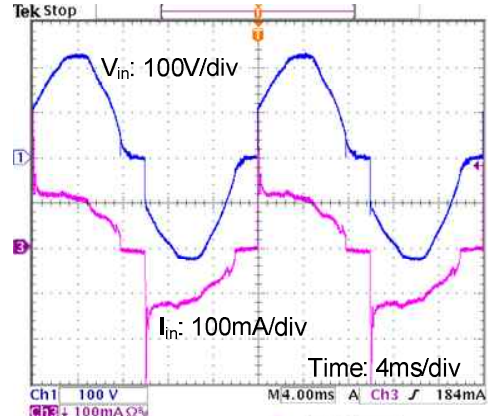

(a) $\theta=20^{\circ}$.

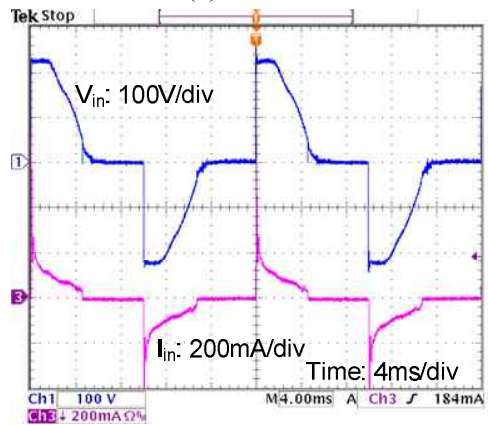

(b) $\theta=90^{\circ}$.

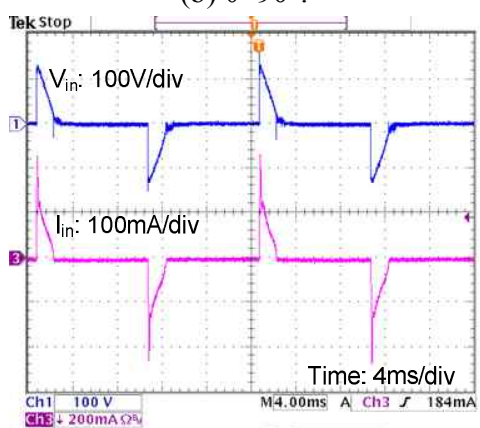

(c) $\theta=160^{\circ}$.

Fig. 13. $V_{\text {in }}$ and line Current $I_{\text {in }}$ at different dimming angle.

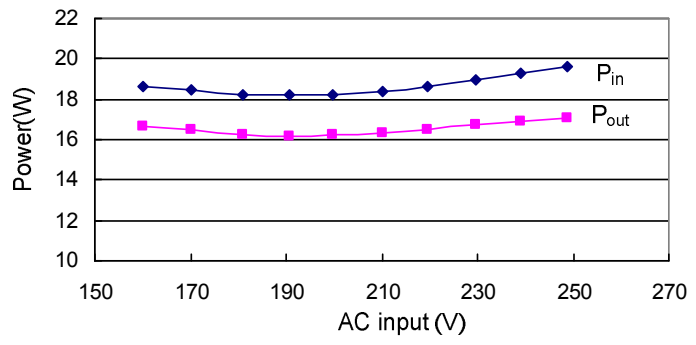

Fig. 14. $P_{\text {in }}, P_{\text {out }}$ vs. $V_{\text {in }} @ \theta=0^{\circ}$.

Fig. 21 shows the LED voltage and current waveforms. The LED current has a line frequency ripple which depends on the output filter capacitance. The larger the capacitance, the smaller the current ripple.

The minimum switching frequency of the prototype at the no dimming condition and a low AC input $(160 \mathrm{Vrms})$ is around $100 \mathrm{kHz}$, and the maximum switching frequency is limited by the L6562 internal maximum switching frequency limitation.

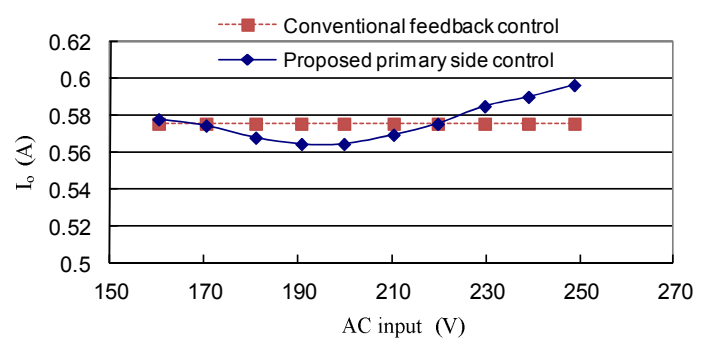

Fig. 15. $\mathrm{I}_{\mathrm{o}}$ vs. $\mathrm{V}_{\text {in }} @ \theta=0^{\circ}$.

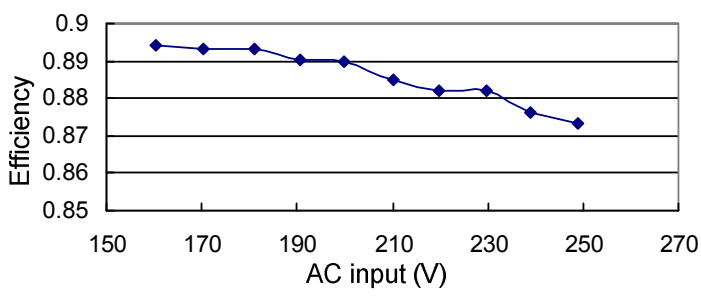

Fig. 16. Efficiency vs. $V_{\text {in }} @ \theta=0^{\circ}$.

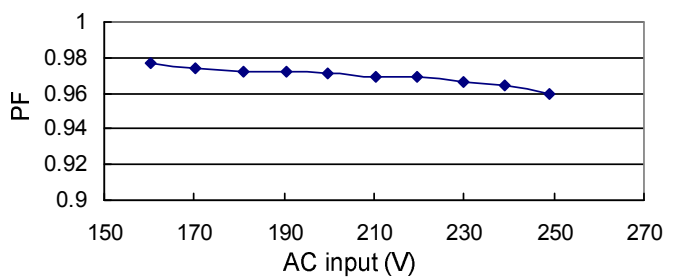

Fig. 17. PF vs. $V_{\text {in }} @ \theta=0$.

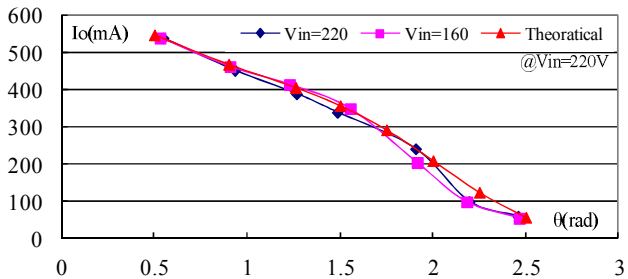

Fig. 18. $\mathrm{I}_{\mathrm{o}}$ vs. dimming angle $\theta$ (rad).

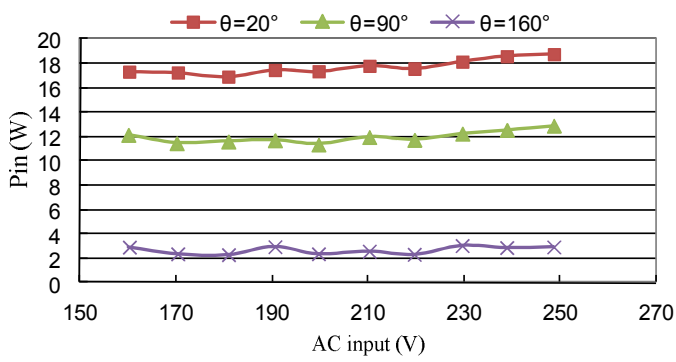

Fig. 19. $P_{\text {in }}$ Vs. $V_{\text {in }}$ at different dimming angle $\theta$.

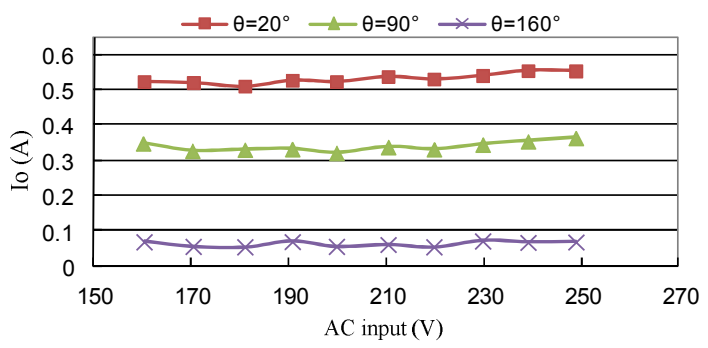

Fig. 20. $\mathrm{I}_{\mathrm{o}}$ vs. $\mathrm{V}_{\text {in }}$ at different dimming angle $\theta$. 


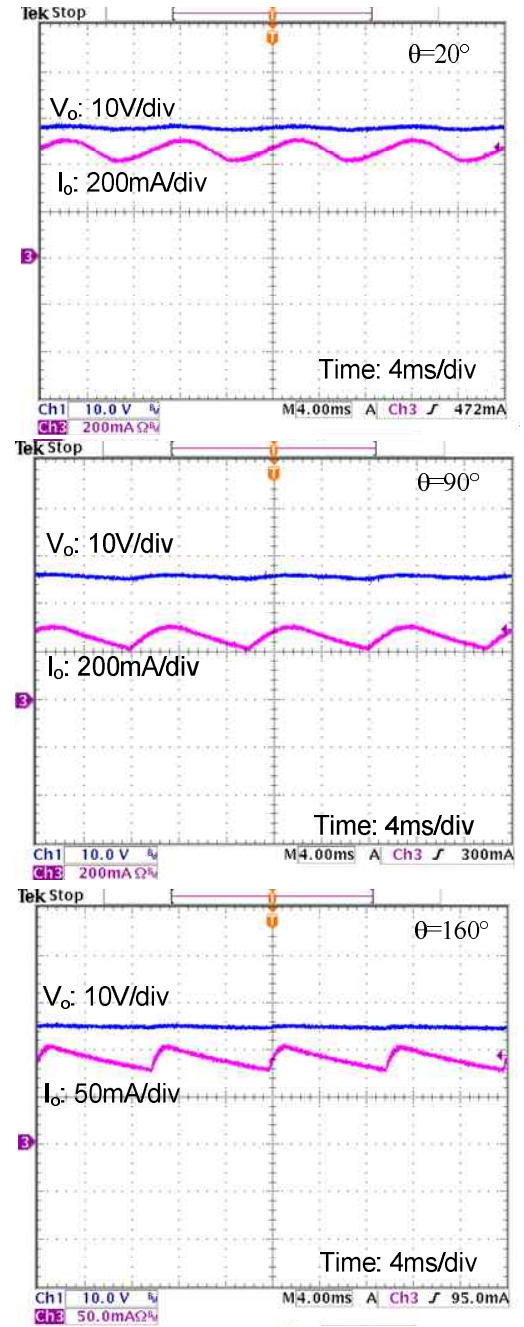

Fig. 21. $\mathrm{I}_{\mathrm{o}}$ and $\mathrm{V}_{\mathrm{o}}$ at different dimming angle $\theta$.

\section{CONCLUSIONS}

This paper proposes a primary side constant power control scheme for TRIAC dimmable LED drivers. With the proposed control scheme, the input power can be controlled by the TRIAC dimming angle and it is not affected by AC input voltage variations. Therefore, the output power can also be controlled with a given conversion efficiency. For the LED load, since the output voltage is nearly constant, the output current can be changed by controlling the input power. In addition, a conventional isolated feedback circuit is not needed, which dramatically simplifies the whole circuit. Considering the output voltage variation in practical applications, the voltage compensation method is also presented to improve the performance of the proposed feedforward control scheme. The implementation of the proposed primary side control scheme for a BCM Flyback converter with PCM control and constant on time control is analyzed. A $15 \mathrm{~W}$ prototype based on PCM control is implemented and tested. The experimental results from the prototype verify the theoretical analysis and the advantages mentioned above.

Since a lot of primary side control schemes for LED driver applications have been proposed in recent years, a comparative study of these control schemes based on a common base is necessary and will be a future work. This study should consider the output current accuracy, sensitivity to parameter tolerances, delay time effect, cost, efficiency, etc.

\section{ACKNOWLEDGMENT}

This work is supported by the National Nature Science Foundation of China under grant 50907061, 51277161, 51007081, and the Fundamental Research Funds for the Central Universities (No. 2013QNA4022).

\section{REFERENCES}

[1] N. Narendran and Y. Gu, "Life of LED-based white light sources," J. Display Technology, Vol. 1, No.1, pp. 167-171, Sep. 2005.

[2] J. Zhang, L. Xu, X. Wu, and Z. Qian, "A precise passive current balancing method for multioutput LED drivers," IEEE Trans. Power Electron., Vol. 26, No. 8, pp. 2149-2159, Aug. 2011

[3] N. Chen and H. S. Chung, "A driving technology for retrofit LED lamp for fluorescent lighting fixtures with electronic ballasts," IEEE Trans. Power Electron., Vol. 26, No. 2, pp. 588-601, Feb. 2011.

[4] X. Qiu, S.-C. Wong, and C. K. Tse, "Resonance-Assisted Buck Converter for Offline Driving of Power LED Replacement Lamps," IEEE Trans. Power Electron., Vol. 26, No. 2, pp. 532-540, Feb. 2011

[5] A. Tjokrorahardjo, "Simple TRIAC dimmable compact fluorescent lamp ballast and light emitting diode driver," in Proc. IEEE Applied Power Electronics Conf., pp. 1352-1357, 2010.

[6] D. Rand, B. Lehman, and A. Shteynberg, "Issues, models and solutions for TRIAC modulated phase dimming of LED lamps," in Proc. IEEE Power Electronics Specialists Conf., pp. 1398-1404, 2007.

[7] L. Xu, H. Zeng, J. Zhang, and Z. Qian, "A primary side controlled WLED driver compatible with TRIAC dimmer," in Proc. IEEE Applied Power Electronics Conf., pp. 699-704, 2011.

[8] Energy Star Program Requirements for Solid State Lighting Luminaires Eligibility Criteria - Version 1.1, Dec. 19, 2008.

[9] D. G. Lamar, J. S. Zuniga, A. R. Alonso, M. R. Gonzalez, M. M. H. Alvarez, "A very simple control strategy for power factor correctors driving high-brightness LEDs," IEEE Trans. Power Electron., Vol.24, No. 8, pp. 2032-2042, Aug. 2009.

[10] Q.C. Hu and R. Zane, "A 0.9 PF LED driver with small LED current ripple based on series-input digitally-controlled converter modules," in Proc. IEEE Applied Power Electronics Conf., pp. 2314-2320, 2010.

[11] D. Gacio, J. M. Alonso, A. J. Calleja, J. Garcia, and M. Rico-Secades, "A universal-input single-stage high-power-factor power supply for HB-LEDs based on integrated buck-flyback converter," IEEE Trans. Ind. 
Electron., Vol. 58, No.2, pp.589-599, Feb. 2011.

[12] J. Alonso, J. Vina, D. Gacio, G. Martinez, and R. Osorio Sanchez, "Analysis and design of the integrated double buck-boost converter as a high-power-factor driver for power-LED lamps," IEEE Trans. Ind. Electron., Vol. 59, No. 4, pp. 1689-1697, Apr. 2012.

[13] S. Huynh, M. Chen, C. Xiao, and M. Yu, "Primary side constant output current controller." U.S. Patent 2006/0285365 A1, Dec. 2006.

[14] M. Granti, "Regulating Output Current From A Primary side Power Converter by Clamping an error signal." U.S. Patent 2008/025965 A1, Oct. 2008.

[15] T.-y. Yang, C.-C. Li, and F.-C. Tsao, "Primary-Side Controlled switching regulator" U.S. Patent 2008/0136393 A1, Jun. 2008.

[16] S. Du, F. Zhu, and P. Qian, "Primary side control circuit of a flyback converter for HBLED," in Proc. IEEE International Symposium on Power Electronics for Distributed Generation Systems, pp. 339-342, 2010.

[17] M. Negrete, W. Gu, and Z Li, "Dimmer-Controlled LEDs Using Flyback Converter with High Power Factor," US 2010/0141177A1, Jun. 2010

[18] H. Eom, C. Lee, T.Yang, and S. Yang, "Design optimization of TRIAC-dimmable AC-DC converter in LED lighting," in Proc. IEEE Applied Power Electronics Conf., pp. 831-835,2012.

[19] X. Xie, J. Wang, C. Zhao, Q. Lu, and S. Liu, "A Novel output current estimation and regulation circuit for priamry side controlled high power factor single-stage flyback LED driver," IEEE Trans. Power Electron, Vol. 27, No. 11, pp. 4602-4612, Nov. 2012

[20] J. Zhang, H. Zeng, and T. Jiang, "A primary side control scheme for high-power-factor LED driver with TRIAC dimming Capability," IEEE Trans. Power Electron,, Vol. 27, No. 11, pp. 4619-4629, Nov. 2012

[21] P. L. Huang, D. Chen, C. J. Chen, and Y. M. Chen, "An adaptive high-precision over-power protection scheme for primary-side controlled flyback converters," IEEE Trans. Power Electron., Vol. 26, No. 10, pp. 2817-2824, Oct. 2011.

[22] H. M. Pang and P. Bryan, "A stability issue with current mode control flyback converter driving LEDs," in Proc. IEEE International Power Electronics and Motion Control Conf., pp.1402-1406, 2009.

[23] T. Chern, L. Liu, C. Huang, Y. Chern, and J. Kuang, "High power factor Flyback converter for LED driver with Boundary Conduction Mode control," in Proc. IEEE Industrial Electronics and Applications, pp.2088-2093, 2010.

[24] $18 \mathrm{~W}$ single-stage offline LED driver, Application Note, AN3111, available at www.st.com

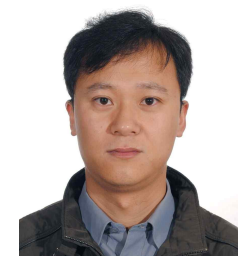

Junming Zhang received his B.S., M.S. and $\mathrm{Ph} . \mathrm{D}$. in Electrical Engineering from Zhejiang University, Hangzhou, China, in 1996, 2000 and 2004, respectively. $\mathrm{He}$ is currently an Associate Professor in the College of Electrical Engineering, Zhejiang University. His research interests include power electronics system integrations, power management, high performance DC/DC converters and inverters.

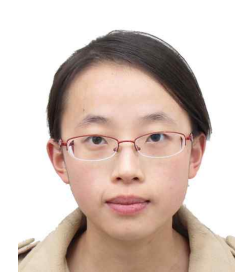

Ting Jiang was born in Sichuan, China, in 1989. She received her B.S. in Electrical Engineering from Zhejiang University, Hangzhou, China, in 2011, where she is currently working toward her M.S. in Electrical Engineering. Her current research interests include the various current sharing methods for multi-channel LED drivers.

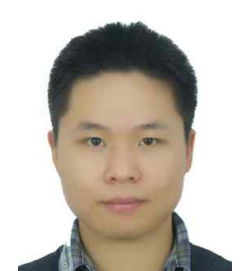

Lianghui Xu was born in Anhui, China, in 1988. He received his B.S. and M.S. in Electrical Engineering from Zhejiang University, Hangzhou, China, in 2008 and 2011, respectively. $\mathrm{He}$ is currently an Engineer in the Electric Power Research Institute, Nanjing, China.

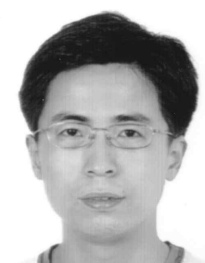

Xinke Wu was born in Jiangsu, China, in 1978. He received his B.S. and M.S. in Electrical Engineering from the Harbin Institute of Technology, Harbin, China, in 2000 and 2002, respectively. He received his $\mathrm{Ph} . \mathrm{D}$. in Electrical Engineering from Zhejiang University, Hangzhou, China, in 2006. He is currently an Associate Professor in the College of Electrical Engineering of Zhejiang University. His current research interests include the soft switching of power converters, high efficiency DC-DC power converters and power electronics system integrations. 